\title{
Consolidation Quality and Mechanical Performance of Stamp Formed Tailored Blanks Produced by Rapid AFP
}

\author{
T.K. Slange ${ }^{1,2}$, L.L. Warnet ${ }^{1, a)}$, W.J.B. Grouve ${ }^{1}$ and R. Akkerman ${ }^{1,2}$ \\ ${ }^{1}$ Department of Mechanical Engineering, University of Twente, P.O. box 217, 7500 AE Enschede, The Netherlands \\ ${ }^{2}$ ThermoPlastic composites Research Center (TPRC), P.O. box 770, 7500 AT Enschede, The Netherlands

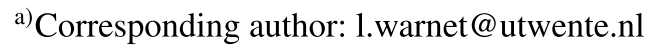

\begin{abstract}
.
Stamp forming is a rapid manufacturing technology used to shape flat blanks of thermoplastic composite material into threedimensional components. The combination with rapid AFP as blank manufacturing technology can further extend the applicability of stamp forming by allowing rapid lay-up of tailored blanks and offering partial preconsolidation. In an experimental study it is demonstrated that high quality laminates with good flexural strength can be obtained by following this process route. The consolidation of ply-drop regions is demonstrated by flat laminates with a thickness step. The influence of fiber orientations, blank-tooling misalignments and AFP tolerances is investigated.
\end{abstract}

\section{INTRODUCTION}

Thermoplastic composites offer great potential for rapid manufacturing of high performance lightweight structures. Stamp forming is such a rapid manufacturing technology. It is used to shape flat blanks into three-dimensional components in short cycle times, making the process attractive for large series production in both the automotive and aerospace industry. However, the current use of uniform thickness blanks limits the application of stamp forming to simple secondary components. The development of automated lay-up technologies, such as advanced fiber placement (AFP), has made highly tailored lay-ups and near net-shape blank manufacturing possible [1]. Combining these two techologies seems promising, as it extends the applicability of stamp forming by using optimized lay-ups, which increase component performance and reduce weight, cost and production scrap [2]. Another benefit of AFP is the combined lay-up and (partial) preconsolidation of blanks. This means that an additional preconsolidation step can potentially be omitted from the process route. This is beneficial, as commonly used preconsolidation methods, such as press and autoclave consolidation, are time consuming and expensive. The proposed process route is shown in Fig. 1.

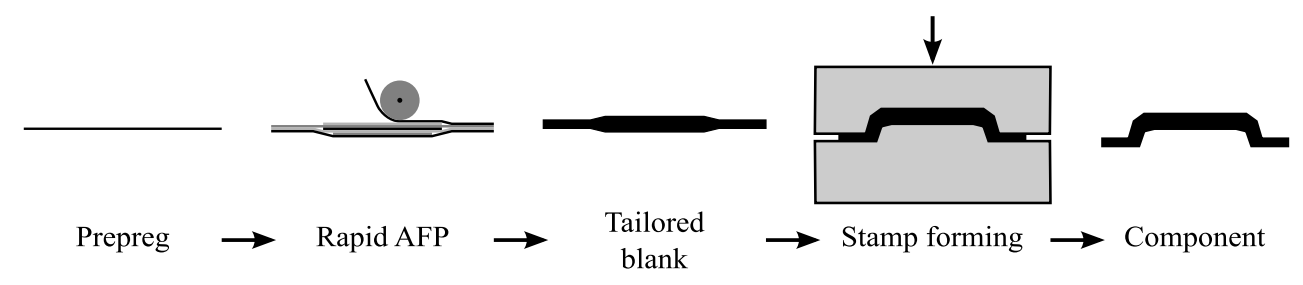

FIGURE 1. Proposed rapid manufacturing process route from prepreg to stamp formed component.

However, the combination of rapid AFP with stamp forming without additional preconsolidation has yet to be proven, although first attempts have been made by Slange et al. [3,5] and Zenker et al. [4]. As a consequence of the high lay-up rates that are desired to maintain high productivity, the degree of consolidation after AFP usually remains low. Hence, additional bonding between plies and void elimination has to take place during the stamp forming process. This can be challenging, as there is very little time available for consolidation, typically a few seconds, due to the high 
cooling rates that occur once the tooling is closed. Furthermore, any defects that may arise during AFP, such as gaps, overlaps and early or late fed or cut tows, have to be eliminated.

This work aims to demonstrate that high quality components can be obtained when stamp forming tailored blanks which are laid up by rapid AFP. Firstly, the consolidation quality and mechanical performance are evaluated based on flat laminates with uniform thickness. Secondly, the consolidation of ply-drop regions, which are inherently present in tailored blanks, is evaluated based on flat laminates with a thickness step. Various lay-ups are considered in order to investigate the influence of fiber orientations and intentional blank-tooling misalignments are introduced to include the influence of misalignments and AFP tolerances.

\section{EXPERIMENTAL WORK}

\section{Materials and Blank Manufacturing}

Blanks were produced from TenCate Cetex ${ }^{\circledR}$ TC1200 (TC) and Cytec APC-2 (CY) 1/4 inch wide unidirectional $\mathrm{C} / \mathrm{PEEK}$ prepreg. Both prepregs have a fiber volume fraction of approximately $60 \%$, but their fiber-matrix distribution and void content differs, as shown in Fig. 2. While the TC prepreg has a very uniform distribution and is void-free, a matrix rich surface and intralaminar micro-voids are present in the CY prepreg. The consolidated ply thickness of both prerpegs was $0.14 \mathrm{~mm}$. The blanks were manufactured using a Coriolis AFP machine with laser heating at a rate of $200 \mathrm{~mm} / \mathrm{s}$ and a nip-point temperature of approximately $460^{\circ} \mathrm{C}$. Consolidation of the blanks was imperfect due to the high lay-up rate. Both interlaminar (TC and CY) and intralaminar (CY) voids remain in the blanks, with large voids in the pockets next to dropped plies in the tailored blanks. Additionally, press-consolidated laminates were prepared as a reference for the mechanical testing.

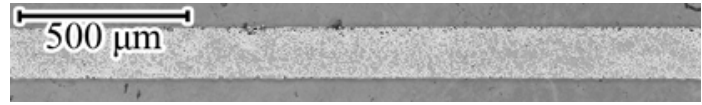

(a) TC

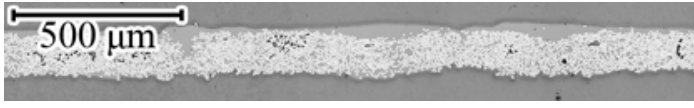

(b) $\mathrm{CY}$

FIGURE 2. Cross-sectional micrographs of the used prepregs.

\section{Consolidation and Mechanical Testing of Rapid AFP Blanks}

Uniform thickness cross-ply laminates with $[0 / 90]_{4 s}$ lay-up were used for the evaluation of consolidation quality and mechanical performance after stamping. The blanks were preheated to $420^{\circ} \mathrm{C}$ in an IR-oven, automatically transferred to the press and stamped at pressure of $100 \mathrm{bar}$ and tooling temperature of $250^{\circ} \mathrm{C}$.

The consolidation quality after stamping was evaluated based on C-scan and cross-sectional micrographs and compared to a press-consolidated reference laminate. Mechanical performance was characterized through 3-point bending tests on specimens cut from the blanks according to ASTM D7264. A span to thickness ratio of 20 was used, while the thickness and width of the specimens were approximately $2.2 \mathrm{~mm}$ and $15 \mathrm{~mm}$, respectively. Three specimens were tested per laminate.

\section{Consolidation of Ply-drops in Tailored AFP Blanks}

Tooling with a thickness step on one side was used for consolidation experiments on tailored blanks with non-uniform thickness, as shown in Fig. 3. The thickness step in the tooling had a height equivalent to four plies $(0.56 \mathrm{~mm})$ and a slope of 1:22. The blanks were laid up with an intentional negative shift of $1.6 \mathrm{~mm}$ with respect to the slope in order to guarantee pressure on the ends of the dropped plies. Three different ply-drop configurations were compared. Firstly, blanks were laid up containing $90^{\circ}$ plies which are dropped between $0^{\circ}$ plies. This should allow filling of the pocket next to the dropped ply by transverse flow of the $90^{\circ}$ ply. Secondly, blanks with $\pm 45^{\circ}$ plies dropped between $0^{\circ}$ plies were prepared. Since the tape is always cut perpendicular to the fiber direction, $\pm 45^{\circ}$ plies have a zig-zag edge, rather than an edge which is parallel to the drop. Thirdly, blanks in which $0^{\circ}$ plies are dropped between $\pm 45^{\circ}$ plies. In this case no transverse flow is possible and the pocket should be filled by matrix that is squeezed out of the dropped ply. The exact lay-ups are listed in Table 1. 
TABLE 1. The three different ply-drop configurations. Subscript $L=$ local ply.

\begin{tabular}{c|cc}
\hline Configuration & Lay-up thick section & Lay-up thin section \\
\hline $90^{\circ}$ between $0^{\circ}$ & {$\left[0 / 90_{L} / 0 / 90_{L} / 0 / 90 / 0 / 90\right]_{s}$} & {$[0 / 0 / 0 / 90 / 0 / 90]_{s}$} \\
$45^{\circ}$ between $0^{\circ}$ & {$\left[0 /+45_{L} / 0 /-45_{L} / 0 / 90 / 0 / 90\right]_{s}$} & {$[0 / 0 / 0 / 90 / 0 / 90]_{s}$} \\
$0^{\circ}$ between $45^{\circ}$ & {$\left[+45 / 0_{L} /-45 / 0_{L} /+45 /-45 / 0 / 90\right]_{s}$} & {$[+45 /-45 /+45 /-45 / 0 / 90]_{s}$} \\
\hline
\end{tabular}

The tailored blanks were stamped at conditions identical to the uniform thickness blanks. The blanks were aligned with respect to the tooling by aid of a line laser at an accuracy of $\pm 1 \mathrm{~mm}$. The influence of blank misalignment with respect to the tooling or AFP feed/cut tolerances was investigated by intentionally misaligning the blanks with both a positive or negative shift. The consolidation quality of the ply-drop regions was evaluated based on cross-sectional micrographs.

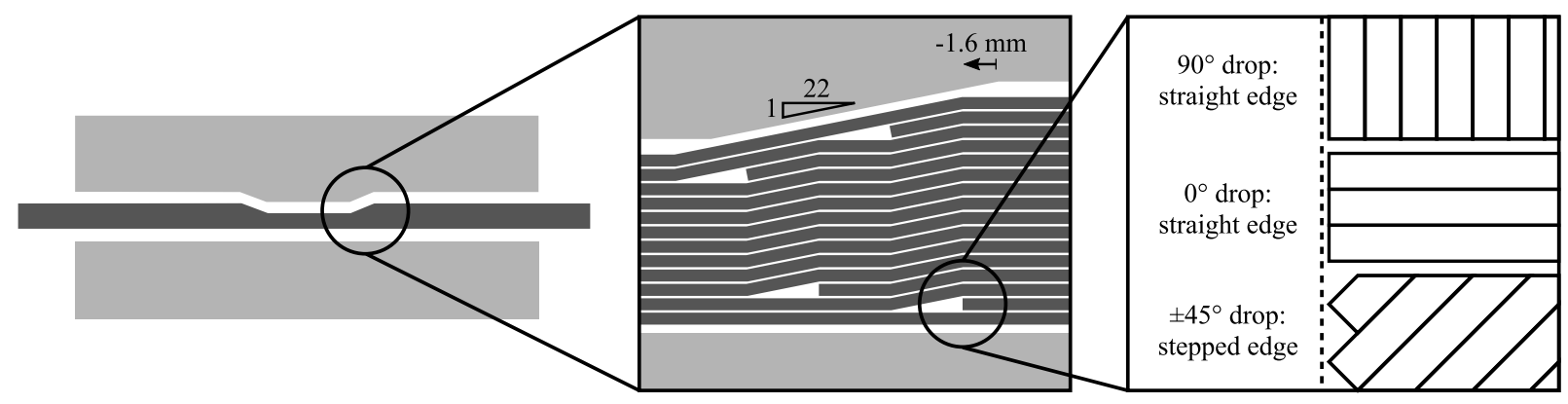

FIGURE 3. Tooling with tapering and a detail of the ply-drop region and ply-drop edge.

\section{RESULTS AND DISCUSSION}

\section{Consolidation and Performance of Rapid AFP Blanks}

Figure 4 (a) compares the mechanical performance of the blanks both before and after stamping. All specimens failed by buckling on the compressive side of the specimen. The performance of the AFP blanks is clearly poor before stamping due to the imperfect consolidation achieved during rapid AFP. However, after stamping all blanks show similar performance compared to the press-consolidated reference blank. This demonstrates that good quality components can be achieved by stamping rapid AFP blanks. Both C-scans and cross-sectional micrographs, shown in Fig. 4 (b-c), confirmed this. TC AFP blanks were completely void-free after stamping. Stamped CY AFP blanks still showed some $(<1 \%)$ intralaminar micro-voids that remained from the used CY prepreg, although these did not affect the 3-point bending performance significantly. The small intralaminar voids are more challenging to remove than the larger interlaminar voids, as was also addressed by Wakeman et al. [6]. All stamped blanks show lower performance than the unstamped press-consolidated blanks. This could be a result of a difference in degree of crystallinity due to the higher cooling rates during stamp forming compared to press consolidation, although this was not confirmed.

\section{Consolidation of Ply-drops in Tailored AFP Blanks}

A selection of cross-sectional micrographs of the ply-drop regions is shown in Fig. 5. Table 2 summarizes the observations made based on the micrographs with respect to the filling of the pockets next to the dropped plies by matrix, fibers and matrix or voids. In all cases a large part of the drop is also filled by material from the surrounding plies. Consolidation is good for $90^{\circ}$ dropped plies, with the pockets filled by both fibers and matrix due to transverse flow of the dropped ply. Consolidation of $0^{\circ}$ and $\pm 45^{\circ}$ dropped plies is more challenging. The fibers are not parallel to the drop, which restricts transverse flow. Moreover, the large pocket at the stepped $\pm 45^{\circ}$ edge requires more flow to fill the pocket. This effect is more critical for the TC prepreg than the CY prepreg, as the non-uniform fiber/matrix distribution of the CY prepreg allows for more material flow due to the matrix rich regions. 


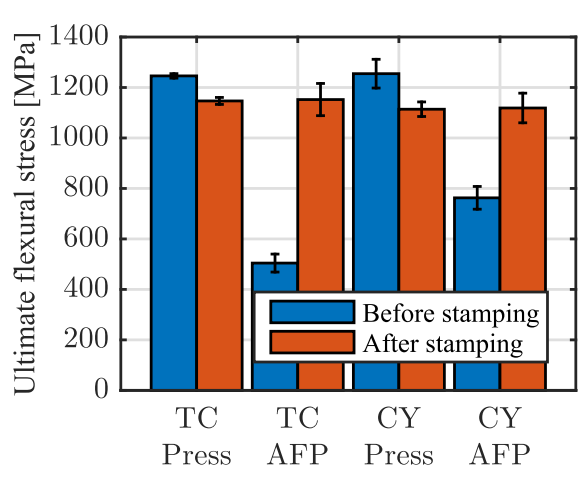

(a)

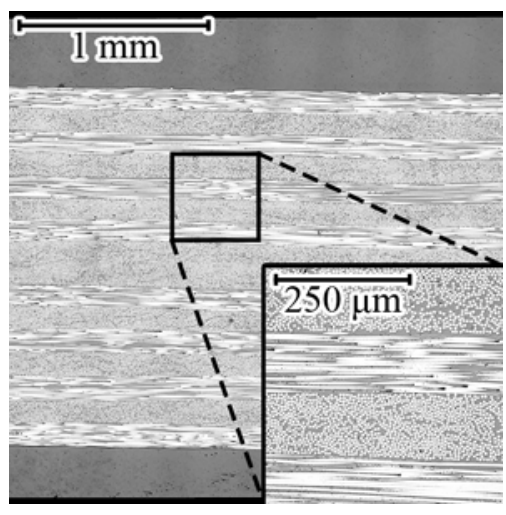

(b)

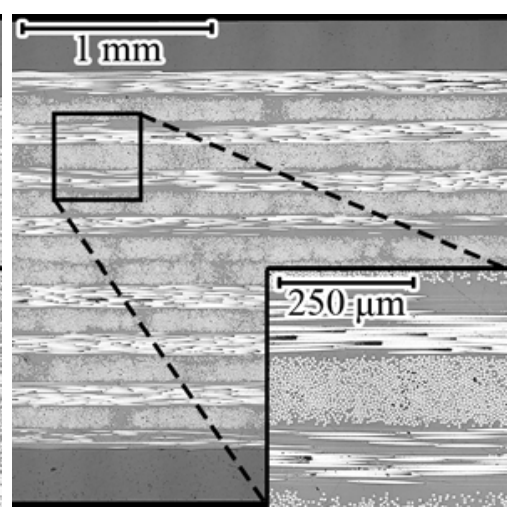

(c)

FIGURE 4. (a) 3-Point bending test results.Cross-sectional micrographs of the stamped AFP blanks for (b) TC (void-free) and (c) CY (intralaminar micro-voids remaining).

Challenges with filling of the pockets became more apparent when the blanks were intentionally misaligned with respect to the tooling. While $90^{\circ}$ dropped plies do not seem to be sensitive to misalignments, $0^{\circ}$ and $\pm 45^{\circ}$ dropped plies do. A positive shift of the blank, i.e. the dropped plies do not extend far enough into the ply-drop region, results in an increased pocket next to the dropped ply, requiring too much material flow to fill this pocket. A negative shift, i.e. the dropped plies extend further into the ply-drop region, reduces the size of the pocket and requires less flow to fill the pocket. In this case consolidation actually improves, indicating that an intentional negative shift during lay-up can be beneficial for consolidation of ply-drops in rapid AFP blanks. Non-rigid tooling may also reduce alignment and AFP accuracy issues, as these issues mainly arise due to the combination of rigid tooling and a local mismatch between the tooling gap and material thickness. This is yet to be confirmed.

TABLE 2. Consolidation quality of ply-drop regions based on cross-sectional micrographs. Ply-drop pocket filling is indicated by: $\mathrm{M}=$ matrix only, $\mathrm{FM}=$ fibers and matrix, $\mathrm{V}=$ void.

\begin{tabular}{lccc}
\hline Configuration & Misalignment $(\mathbf{m m})$ & TC & CY \\
\hline $90^{\circ}$ between $0^{\circ}$ & 0 & $\mathrm{FM}$ & $\mathrm{FM}$ \\
$90^{\circ}$ between $0^{\circ}$ & +3 & - & $\mathrm{FM}$ \\
$90^{\circ}$ between $0^{\circ}$ & -3 & - & $\mathrm{FM}$ \\
$\pm 45^{\circ}$ between $0^{\circ}$ & 0 & $\mathrm{~V}+\mathrm{FM}$ & $\mathrm{M}+\mathrm{FM}$ \\
$\pm 45^{\circ}$ between $0^{\circ}$ & +3 & - & $\mathrm{V}+\mathrm{M}+\mathrm{FM}$ \\
$\pm 45^{\circ}$ between $0^{\circ}$ & -3 & - & $\mathrm{M}+\mathrm{FM}$ \\
$0^{\circ}$ between $\pm 45^{\circ}$ & 0 & $\mathrm{M}+\mathrm{FM}$ & $\mathrm{M}+\mathrm{FM}$ \\
$0^{\circ}$ between $\pm 45^{\circ}$ & +3 & $\mathrm{~V}$ & $\mathrm{M}+\mathrm{FM}$ \\
$0^{\circ}$ between $\pm 45^{\circ}$ & -3 & $\mathrm{M}+\mathrm{FM}$ & $\mathrm{M}+\mathrm{FM}$ \\
\hline
\end{tabular}

\section{CONCLUSIONS AND RECOMMENDATIONS}

An experimental study was performed in order to investigate the feasibility of a novel process route where rapid AFP and stamp forming are combined into a rapid manufacturing chain for tailored components. It was successfully demonstrated that void-free laminates can be obtained after stamp forming, even though blanks are not void-free after rapid AFP. The flexural strength obtained from 3-point bending tests was comparable to press-consolidated blanks.

Stamp forming experiments on tailored blanks with a thickness step of four plies demonstrated that proper consolidation of pockets next to dropped plies is also possible. However, the filling behavior depends on the fiber direction of the dropped ply. $90^{\circ}$ dropped plies allow for good filling of the pocket due to transverse flow and show little sensitivity to misalignments of the blank with respect to tooling or AFP feed/cut inaccuracy. The filling of pockets next to $0^{\circ}$ and $\pm 45^{\circ}$ dropped plies is more critical, as this relies more on percolation flow due to the off-angle fibers. Moreover, 


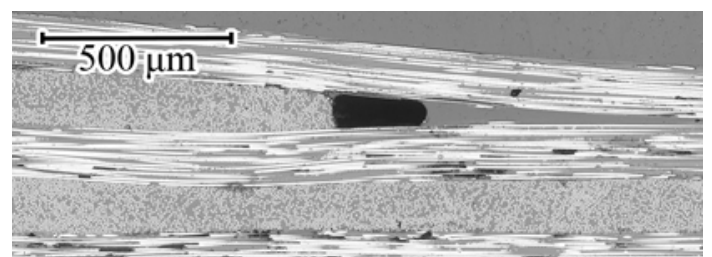

(a) $\mathrm{TC} 90^{\circ}$ between $0^{\circ}$, before stamping

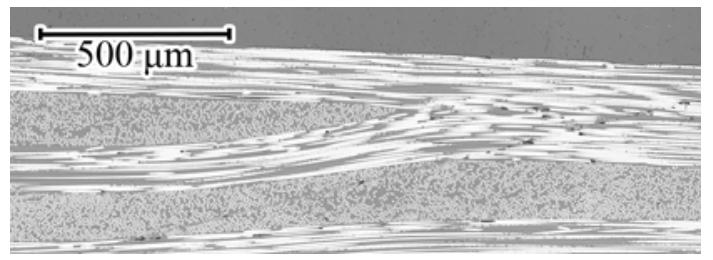

(c) $\mathrm{TC} 90^{\circ}$ between $0^{\circ}, 0 \mathrm{~mm}$ misaligned

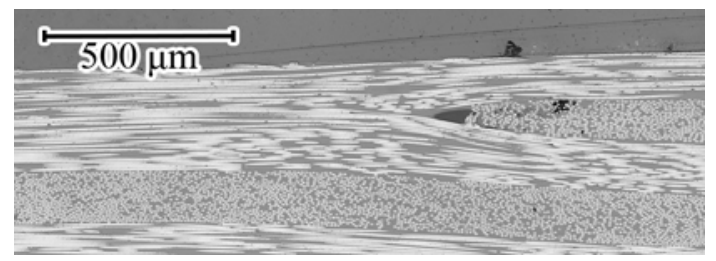

(e) $\mathrm{TC} \pm 45^{\circ}$ between $0^{\circ}, 0 \mathrm{~mm}$ misaligned

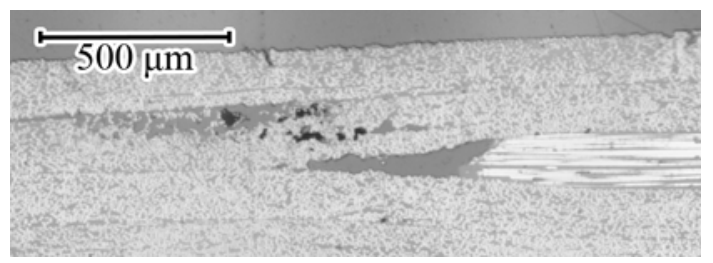

(g) TC $0^{\circ}$ between $\pm 45^{\circ},+3 \mathrm{~mm} \mathrm{~mm}$ misaligned

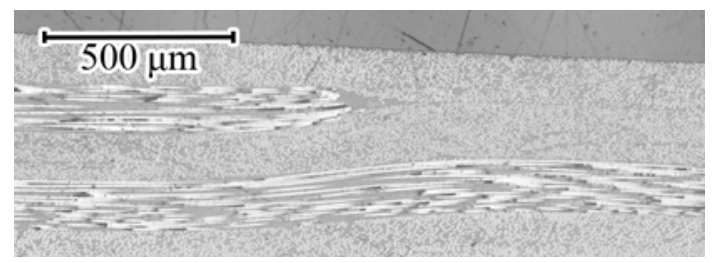

(i) $\mathrm{TC} 0^{\circ}$ between $\pm 45^{\circ}, 0 \mathrm{~mm}$ misaligned

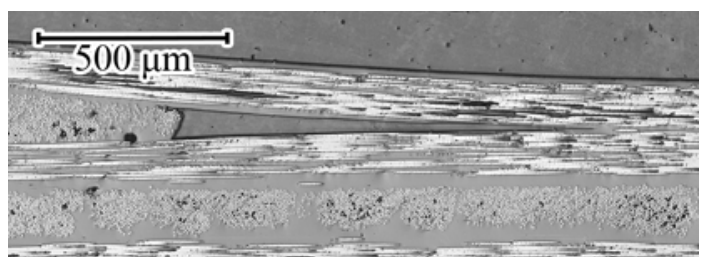

(b) CY $90^{\circ}$ between $0^{\circ}$, before stamping

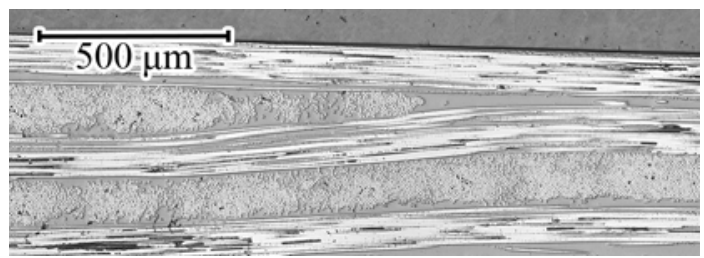

(d) CY $90^{\circ}$ between $0^{\circ}, 0 \mathrm{~mm}$ misaligned

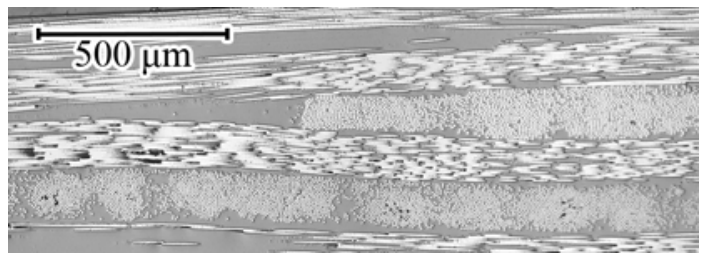

(f) $\mathrm{CY} \pm 45^{\circ}$ between $0^{\circ}, 0 \mathrm{~mm}$ misaligned

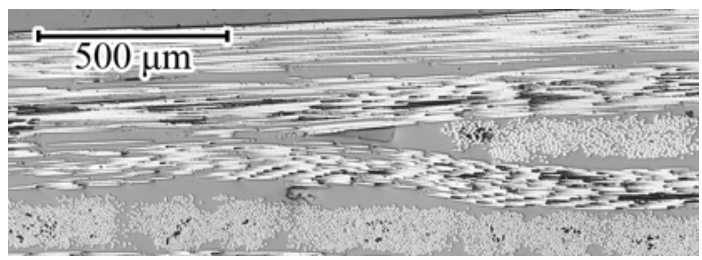

(h) $\mathrm{CY} \pm 45^{\circ}$ between $0^{\circ},+3 \mathrm{~mm}$ misaligned

FIGURE 5. Detail cropped images of cross-sectional micrographs of the ply-drop region. 
the volume of the pocket is much larger in case of $\mathrm{a} \pm 45^{\circ}$ due to the stepped edge that appears during the AFP process applied in this work. $0^{\circ}$ and $\pm 45^{\circ}$ ply-drops are also sensitive to positive misalignments, i.e. the dropped plies do not extend far enough into the ply-drop region, resulting in an increased pocket and requiring more material flow to fill it. Extending the dropped plies further into the ply-drop region can resolve this. Having a more non-uniform fiber-matrix distribution appears to be beneficial for filling.

The current work focused on stamp forming of flat plates, i.e. no actual forming took place. Guaranteeing the high pressure that is required for proper consolidation of the rapid AFP blanks becomes more challenging when forming is included. This is because the applied pressure becomes highly driven by the local material thickness and tooling cavity, especially on surfaces which are close to parallel to the loading direction of the press. Non-rigid tooling might offer a solution here, as this can provide a more hydrostatic pressure. It may also reduce issues with blank-tooling alignments and AFP accuracy, although this is yet to be confirmed. Moreover, the influence of tailoring on forming behavior should be investigated, as the ply-drops and local reinforcement may significantly affect the formation of forming defects.

\section{ACKNOWLEDGMENTS}

This research was carried out under project number F11.4.15563 in the framework of the Partnership Program of the Materials innovation institute M2i (www.m2i.nl) and the Foundation of Fundamental Research on Matter (FOM) (www.fom.nl), which is part of the Netherlands Organisation for Scientific Research (www.nwo.nl). The authors gratefully acknowledge the financial and technical support from the industrial and academic members of the ThermoPlastic composites Research Center (TPRC), as well as the support funding from the Province of Overijssel for improving the regional knowledge position within the Technology Base Twente initiative.

\section{REFERENCES}

[1] T. Stol, S. Hooning, and D. Manten, "Press Forming of Tailored CFRTP Products," in SETEC 11 - 06th International Technical Conference "Advanced Composites, The integrated System" (2011), pp. 185-194.

[2] A. Burkhart and D. Cramer, "Feasibility of Continuous-fiber Reinforced Thermoplastic Tailored Blanks for Automotive Applications," in 5th SPE Automotive Composites Conference $\mathcal{E}$ Exhibition (2005), pp. 1-9.

[3] T. K. Slange, L. Warnet, W. J. B. Grouve, and R. Akkerman, "Influence of Preconsolidation on Consolidation Quality after Stamp Forming of C/PEEK Composites," in ESAFORM 2016: Proceedings of the 19th International ESAFORM Conference on Material Forming, edited by F. Chinesta, E. Cueto, and A.-C. Emmanuelle (AIP Conference Proceedings, 2016).

[4] T. Zenker, F. Bruckner, and K. Drechsler, "Experimental Analysis of Consolidation Processes for Preforms Manufactured by Thermoplastic Automated Fiber Placement," in SAMPE Europe 2017 (2017).

[5] T. K. Slange, L. L. Warnet, W. J. B. Grouve, and R. Akkerman, "Influence of Prepreg Characteristics on Stamp Consolidation," in ESAFORM 2017: Proceedings of the 20th International ESAFORM Conference on Material Forming (AIP Conference Proceedings, 2017).

[6] M. D. Wakeman, P. Blanchard, and J.-A. E. Månson, "Void Evolution During Stamp-Forming of Thermoplastic Composites," in 15th International Conference on Composite Materials (ICCM-15) (2005). 